\title{
Textile Polypropylene Allografts and their Postoperative Tissue Reaction in the Surgery of Inguinal Hernia
}

\author{
DAN BRATU ${ }^{1}$, ADRIAN BOICEAN ${ }^{1}$, CIPRIAN TANASESCU ${ }^{1}$, CIPRIAN SOFARIU2*, ALIN MIHETIU ${ }^{1}$, \\ IOAN SEBASTIAN CERNUSCA MITARIU ${ }^{1}$, LIVIA OGNEAN ${ }^{3}$, COSMIN MOLDOVAN ${ }^{4}$, CORNEL BOITOR ${ }^{1}$ \\ ${ }^{1}$ Lucian Blaga University of Sibiu, Faculty of Medicine, 2A Lucian Blaga Str., 550169, Sibiu, Romania \\ 2Sibiu Pediatrics Clinical Hospital, Radiology and Imaging Clinic, 2-4 Pompeiu Onofreiu Str., 550166, Sibiu, Romania \\ ${ }^{3}$ Sibiu Clinical County Hospital, Neonatology Ward, 2-4 Corneliu Coposu Blvd., 550245, Sibiu, Romania \\ ${ }^{4}$ Titu Maiorescu University of Bucharest, Faculty of Medicine, Witting Clinical Hospital of Bucharest - General Surgery Ward, 22 \\ Dambovnicului Str., 040441, Bucharest, Romania
}

\begin{abstract}
The usage of prosthetic devices in the surgery of parietal defect is, nowadays, essential for a good abdominal wall recovery and prevention of the hernia recurrence. A good and suitable textile allograft should poses one or more, ideally all, of the following characteristics: pliable, strong, non-allergenic and with perfect tissue integration behavior. The aim of this paper is to evaluate the immediate and long term tissue reaction of different textile allografts used in open surgery of inguinal hernia repair.
\end{abstract}

Keywords: allografts, polypropylene mesh, tissue reaction, inguinal, hernia

The treatment of inguinal hernia is almost as old as the concept of medicine itself and has undergone through many key turning points up to modern days of laparoscopic procedures. Each era was marked by some key discoveries both in concepts and in development of materials [1].

Each turning point in this history left its mark and are worth mentioning: Bassini introduced the concept of hernia repair using the posterior wall of inguinal canal and thus laying the base for hernia repair under tension era and E. Shouldice proposing the imbrication of the transverse fascia and strengthening of the posterior wall of inguinal canal by four layers of fasciae and aponeuroses of oblique muscles.

However only some forward thinking surgeons like Lichtenstein, that founded the era of tensiomless hernia repair when the tension of sutured layers was reduced by incisions of the rectal abdominal muscle sheath or the usage of foreign materials, such as allografts [1] and the discovery of synthetic polymers by Carothers in 1935, lead to some impressive clinical results. These discoveries allowed Lichtenstein to publish his well-known first study of its tensionless technique (strengthening the posterior wall of inguinal canal with prosthetic material) on a series of 1,000 operations with Mariex ${ }^{\mathrm{TM}}$ mesh without any recurrence, 5 years after surgery.

After this, many other surgeons started to publish several techniques involving allografts for inguinal hernias, such as Rene Stoppa (using a Dacron mesh situated in preperitoneal space without fixing sutures). The pinnacle of the development of surgical hernia repair was the introduction of the first laparoscopic approach in hernia repair during the 20th century by P. Fletcher, in 1979 [2].

Nowadays, the most commonly used types of meshes are: polypropylene, polyester and e-PTFE. The polypropylene allograft is the most widely used in the past 20 years due to its resistance, stability and low tissue reaction. The polyester ones are being used progressively less frequent due to a lower quality tissue integration and the e-PTFE has the main disadvantage of a higher production cost.

Many authors in most modern publications now state that good results in inguinal hernia repair can only be

* eail: ciprianradusofariu@gmail.com achieved with allografts. A good quality repair of the abdominal wall requires some key factors such as: a good quality mesh, mastering a good technique by the surgeon, choosing the right procedure tailored to the specifics of the inguinal hernia and its anatomic variant and, finally, anchoring the allograft to some good quality and strong local anatomic landmarks.

\section{Experimental part}

Our study is based on a series of 36 patients during a period of 14 months that undergone open inguinal hernia repair with the Lichtenstein II technique using polypropylene allografts (Premilene Mesh ${ }^{\mathrm{TM}}$ ).

Polypropylene is a thermoplastic polymer with a wide array of applications. The presence of methyl in its inner composition vastly improves the mechanical and thermic behavior of the product, in the meanwhile keeping the chemical resistance low [3].

The polypropylene density ranges from 0.895 and 0.92 $\mathrm{g} / \mathrm{cm}^{2}$. It is very flexible and resistant with a variable melting point. The perfect isostatic polypropylene has the melting point at $171^{\circ} \mathrm{C}\left(340^{\circ} \mathrm{F}\right)$. However, this compound is prone to degradation when exposed to heat and UV radiations. Also, the bacterial colonization may lead to polypropylene structural failure.

Porosity is another key element regarding the expected tissue reaction [4]. The pores have to be wider than $75 \mu \mathrm{m}$ in diameter to allow a proper macrophageal, fibroblastic and new blood vessel growth, as well as to let new fibers of collagen to engulf the mesh. The wider the diameter of the pores, the lower is the risk of granulomas to be developed $[5,6]$

An adult person develops an average abdominal pressure of about $170 \mathrm{mmHg}$, the allografts being designed to accommodate pressure peaks of about $180 \mathrm{mmHg}$, a key aspect to take into consideration when choosing the right type of prosthetic implants [5].

Regarding the self-weight of the meshes, there are 3 types of polypropylene allografts available on the market today: High Weight(HW): $95 \mathrm{~g} / \mathrm{cm}^{2}$, Medium Weight (MW): $45 \mathrm{~g} / \mathrm{cm}^{2}$ and Low Weight: $28 \mathrm{~g} / \mathrm{cm}^{2}$.

We chose a mesh that belongs to the LW group, the reason behind this decision residing in several in-vivo 
studies on porcine models that clearly show that after implantation in the pig for 5 months, the mean burst strength and stiffness of HW and MW meshes remains the same, however the LW meshes with an absorbable monofilament in its weave has significant reductions in mean burststrength. This further translates that, after tissue incorporation, the LW polypropylene mesh maintains mean burst strength comparable to MW polypropylene mesh, while becoming less stiff than HW mesh. On a long-term projection, this fact may contribute to a more physiological abdominal wall compliance after LW polypropylene mesh implantation [7]. Furthermore, our decision to use a LW class allograft is supported by some larger clinical trials that demonstrated that the usage of the LW meshes was associated with less feeling of a foreign body by the patient compared to using a HW mesh, what can be considered as prevalence of LW mesh hernioplasty [8].

The mesh we used is being developed with thinner threads and pores larger than $1 \mathrm{~mm}$. Its specific weight is $33 \mathrm{~g} / \mathrm{m}^{2}$ and with less tissue reaction and more elastic in behavior. The elasticity of all lightweight meshes ranges between $20-35 \%$ at $16 \mathrm{~N} / \mathrm{cm}$.

Modern biomaterials have to be both chemical and physical inert, the tissue reaction being in close relationship with the amount of foreign material inserted into the body and the diameter of the pores [9].

The physiological process that starts once the allograft is inserted could be summarized as follows: the nondeveloped type I collagen is being replaced rapidly by type III collagen. In the absence of a foreign material, this transformation process takes places at a much lower rate, the ratio between collagen I and III being modified [10].

The surgical procedure involved was, as stated above, the Lichtenstein II technique. Treatment of the hernia sac was performed differently, according to the type of defect: for external oblique hernias - the dissection, ligature and resection - and for direct hernias a simple invagination of the hernia sac. The prosthesis has been custom-tailored by the surgeon according to the local conditions and landmarks, the allograft used in our study being delivered from the manufacturer in a generic rectangle shape (fig. 1). We did not use pre-formed and pre-cutallografts as this greatly limits the intraoperative options. The openings in the mesh were for the spermatic cord (in male patients) and the anchor points were the classic ones described by the standard Lichtenstein technique (fig. 2). The surgical threads used were Nylon No. $10(66.66 \%)$ and Prolene ${ }^{\mathrm{TM}}$ No. 3.0 and $4.0(33.33 \%)$ being deployed in separate $(83.33 \%)$ and continuous $(16.66 \%)$ sutures. The hemostasis was achieved by the means of electrocautery or ligation, in the case of larger blood vessels. In all cases we provided drainage of the subaponevrotic space.

\section{Results and discussions}

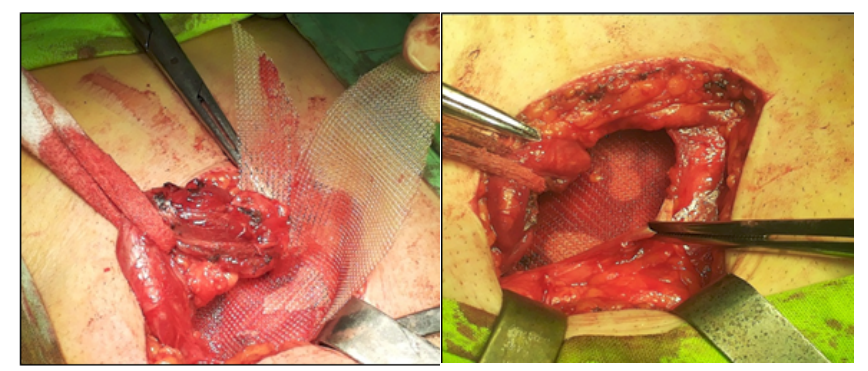

Fig. 1. Placing and custom trimming the textile allograft to Fig. 2. The final montage
The 36 patients in this study had a male to female ratio of $75 \%$ males and $25 \%$ females, this being in total accordance with the worldwide distribution for this type of surgical pathology. The mean hospitalization time was 4.4 days. The postoperative drainage was about $10 \mathrm{~mL}$ per $24 \mathrm{~h}$, being kept in place for an average of 2.6 days and had the key role of diminishing the local pressure upon the allograft but also to prevent an unwanted contamination and thus a poor tissue integration.

We had 1 case of large postoperative hematoma that required surgical reintervention without the allograft removal though.

Monitoring the patients after discharge involved abdominal ultrasound control at 1 month and 6 months respectively, the investigation being performed by the same doctor and with the same ultrasound device, in order to reduce to a minimum the artifacts and false interpretations inherent when involving different personnel with different imaging machines.

Thus, at 1-month check-up, $22.2 \%$ of patients developed seromas (without clinical signs), subcutaneous surgical thread granulomas (13.8\%), granulomatous subcutaneous fibrotic band development (8.3\%) and granulomatous over the mesh fibrotic band development in $5.5 \%$ of cases (figs. 3 and 4).

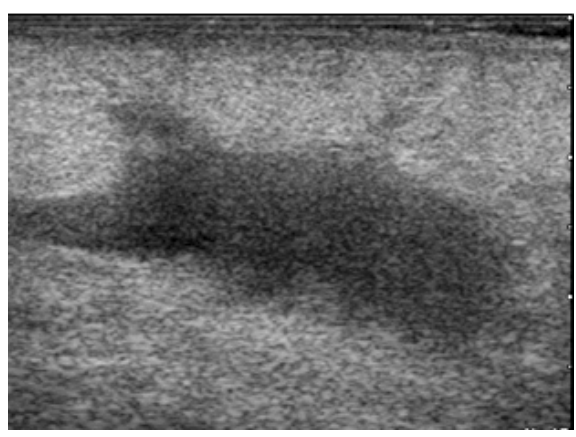

Fig. 3.

Postoperative seroma ultrasound aspect

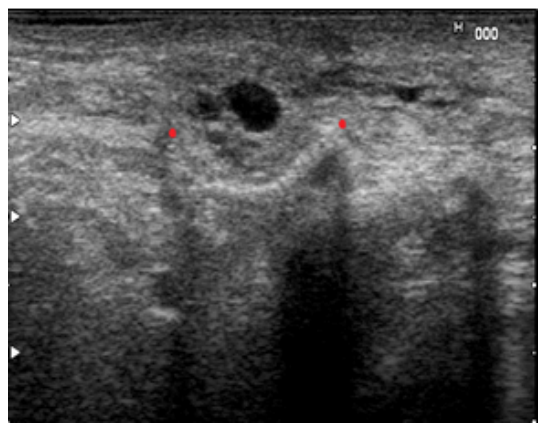

Fig. 4. Allograft and seroma. Ultrasound aspect

At 6-months check-up the seromas do not show up on the ultrasound investigations, in $5.5 \%$ of cases we determined lymph node adenopathy (fig. 5) with 1 case presenting relapse of the hernia (fig. 6). In $27.7 \%$ we can still visualize the mesh but in $72.3 \%$ the allograft was not visible during the ultrasound investigation, this clearly showing that the mesh was fully integrated.

We can see a rather high percent of small-sized postoperative seromas, without clinical signs that might reside in the explanation of an enzymatic activity and in a tissue reactivation that is overrun in the immediate postoperative period. In their composition we can find lymph, proteins, blood (small amounts), fibrin, LDH, white blood cells (WBC). The presence of WBC with neutrophilia at higher values locally then in the blood stream clearly indicates a local tissue activity $[10,11]$.

Granulomas are another type of tissue reactivity to foreign material, but, due to the small amount of it, the reaction is an organized one and somehow limited to the immediate 


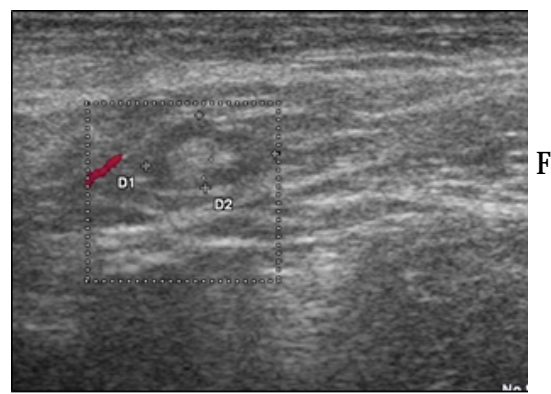

Fig. 5. Ultrasound aspect of the adenopathy

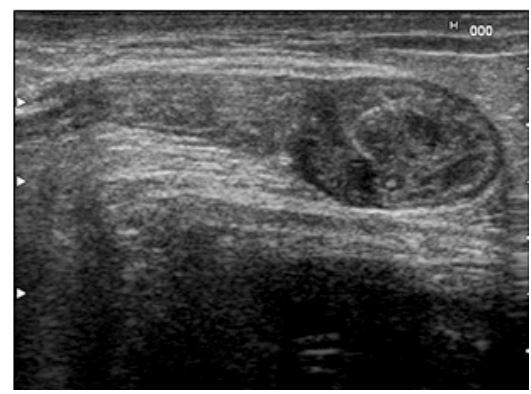

Fig. 6. Hernia relapse, ultrasound exam

area of the surgical knot. The persistence at 6 months of a lymph node reaction clearly supports this theory, as it is too far away from the initial allograft-tissue contact.

Patients with the presence of seromas at the 1-month mark take about $20 \%$ of the those that at 6 -months checkup the ultrasound exam still visualize the presence of the allograft, and so with a tissue integration partially completed.

The case with a hernia relapse is the one that needed surgical reintervention. Excluding the anatomical and morphopathological factors that can lead to a relapse we can now state that exposing the allograft to a supplementary septic intraoperative time or local high tension (for example hematoma) are factors just as important and can influence the structural integrity, elasticity and tissue integration of the mesh.

The tissue reactivity in the form of seromas, granulomas or lymph-node reaction is being identified in a rather large number of cases from our study and can be explained by the surgical technique, materials used and tissue properties, by the immune/inflammatory response of each and every patient, their body being the key element regarding a complete and accurate integration of the allograft at the tissue level.

\section{Conclusions}

The use of polypropylene textile allografts represents an efficient technique for restoring the anterior abdominal wall integrity. The contact of tissues with the mesh produces a local inflammatory response but the evolution towards surgical complications is limited and a delay in a full tissue integration does not translate into immediate relapse of the hernia sac. The polypropylene has physical, chemical and biological properties clearly demonstrated and has favorable quality to price ratio, being nowadays the most widely used allograft in the treatment of inguinal hernias.

Acknowledgements: This study, being a retrospective one, did not require a written consent from the patients involved. The authors declare no conflict of interests and no sponsorship was provided by the manufacturer of the mesh involved in this study. All authors have read and approved this publication and had equal scientific contribution in publishing this material.

\section{References}

1.LEGUTKO ], PACH R, SOLECKI R, MATY]A A, KULIG ] . [The history of treatment of groin hernia]. Folia medica Cracoviensia. 2008;49(12): $57-74$.

2.LAU WY. History of treatment of groin hernia. World journal of surgery. 2002;26(6):748-59.

3.POTECA TD, MIHAILA DE, IONESCU SO, POTECA AG, TAMPA M, MATEI C. Types of Polymeric Meshes Used to Repair Abdominal Wall Defects., Mat Plast., 50, no. 2, 2013, p.134

4.BIONDO-SIMOES MDE L, MORAIS CG, TOCCHIO AF, MIRANDA RA, MOURA PA, COLLA K, et al. Characteristics of the fibroplasia and collagen expression in the abdominal wall after implant of the polypropylene mesh and polypropylene/polyglecaprone mesh in rats. Acta cirurgica brasileira / Sociedade Brasileira para Desenvolvimento Pesquisa em Cirurgia. 2016;31(5):294-9.

5.BRINGMAN S, CONZE J, CUCCURULLO D, DEPREST J, JUNGE K, KLOSTERHALFEN B, et al. Hernia repair: the search for ideal meshes. Hernia : the journal of hernias and abdominal wall surgery. 2010;14(1):81-7.

6.BILSEL Y, ABCI I. The search for ideal hernia repair; mesh materials and types. IntJ Surg. 2012;10(6):317-21.

7.COBB WS, BURNS JM, PEINDL RD, CARBONELL AM, MATTHEWS $B D, K E R C H E R ~ K W, E T$ AL. Textile analysis of heavy weight, midweight, and light weight polypropylene mesh in a porcine ventral hernia model. The Journal of surgical research. 2006;136(1):1-7.

8.DEMETRASHVILI Z, KHUTSISHVILI K, PIPIA I, KENCHADZE G, EKALADZE E. Standard polypropylene mesh vs lightweight mesh for Lichtenstein repair of primary inguinal hernia: a randomized controlled trial. Int J Surg. 2014;12(12):1380-4.

9.BOLOCAN, A. ION, D., CONSTANTINESCU, S., LUCA, A.D., PADURARU, D.N. Randomised Trial Comparing Polypropylene Mesh and Polyvinylidene Fluoride Mesh in the Surgery. Mat Plast., 49, no. 3, 2012, p. 209

10.BROWN CN, FINCH JG. Which mesh for hernia repair? Annals of the Royal College of Surgeons of England. 2010;92(4):272-8.

11.WOTTON FT, AKOH JA. Rejection of Permacol mesh used in abdominal wall repair: a case report. World journal of gastroenterology. 2009;15(34):4331-3

Manuscript received: 12.08 .2016 